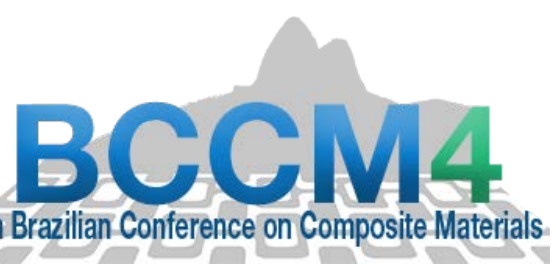

\title{
DEVELOPMENT OF KEVLAR COMPOSITES FOR BALLISTIC APPLICATION
}

\author{
Viviane M Fonseca $^{(1)}$, Erick J.P. A Oliveira ${ }^{(1)}$, Pedro T Lima ${ }^{(1)}$, Laura H Carvalho ${ }^{(2)}$ \\ (1) Department of Textil Engineering, Universidade Federal do Rio Grande do Norte, Brazil \\ (2) Department of Material Engineering, Universidade Federal de Campina Grande, Brazil
}

https://doi.org/10.21452/bccm4.2018.09.04

\begin{abstract}
Laminated ballistic composite panels are an important part of hard-plate protective body armour and may be subjected to a wide variety of impact conditions depending on the projectile, impact velocity and armour construction. Kevlar fiber is the type of reinforcement most widely applied in these materials. Within the composites industry, woven, knitted and nonwoven reinforcements made of glass fiber, carbon fiber and aramid fibers are now widely accepted as being technical textile products. The applied of textile fabrics has generally provided a lower composite manufacturing cost and a higher damage tolerance. The highstrength, high-modulus Kevlar 49 fiber is widely used today because of its superior properties. Aramid fibers are known for their large hardness and resistance to penetration. Due to their toughness aramid fibers are used where high impenetrability is required, e.g. bulletproof vests, bike tyres, airplanes wings, and sport equipment. In this work, Kevlar nonwoven, obtained by cutting apart of the bulletproof, as used for reinforced polyester composites and kevlar fabrics manufacturing using handcraft process reinforced polyester will be tested using .38 weapons in close range in order to simulate a real situation (confrontation). The impact properties of the reinforcements will also be determined in the same situations and their behavior after tests are compared. The preliminary results after the gunshot test demonstrated the efficiency of the reinforcements in the ballistic for bulletproof vest and the developed fabrics. This fact evidences the feasibility of using the fabric as a ballistic application. The performance of the composite under gunshot test for polyester reinforced kevlar fabrics of the composite was performed in a 3 different sample. The results showed the effective action of the composites developed for application in shields. Independently of the reinforcement contents, all the composites presented resistance to shooting using caliber, 38 and 40 . For the use of the caliber; 40 the material presented a very satisfactory result, considering the level of damage of this type of ammunition This result is indicative that the material developed can be used in shields.
\end{abstract}

Keywords: aramid fabric; polyester, ballistic, kevlar, bulletproof 


\section{INTRODUCTION}

Laminated ballistic composite panels are an important part of hard-plate protective body armour and may be subjected to a wide variety of impact conditions depending on the projectile, impact velocity and armour construction. kevlar is the type of reinforcement most widely applied in these materials.

Within the composites industry, woven, knitted and nonwoven reinforcements made of glass fiber, carbon fiber and aramid fibers are now widely accepted as being technical textile products. Traditionally the use of textile fibers is associated with clothing and household textiles. However, with the increasing technological evolution verified in recent years its use in other areas of engineering has been gaining prominence, mainly when it is necessary high performance. Thus many researchers around the world have been searching to innovate and maximize the potential of different fibrous materials in combination with polymer matrices, creating products with unique properties called composites [1-3].

The chemical and structural combination of different polymers produced a new class of textile products called high performance fibers with unique properties to be used in a wide variety of engineering fields [4,5]. For the development of these materials, a wide range of synthetic, artificial or natural fibers may be used. However, with the high technology domain, high performance fibers have superior characteristics for general specific applications due to compared then mechanical properties. These fibers present superior resistance and modulus of elasticity to the conventional synthetic fibers, becoming an important field to be explored in technological applications [6]. Aramid, UHMWPE and carbon fibers are examples of high performance fibers.

High specific strength, high specific module and excellent chemical resistance are attractive properties that polymer composites offer when compared to metallic materials. However, due to the anisotropic characteristic of the material, the mechanical strength is closely related to the orientation of the reinforcement provided by high-performance fibers where the mechanical strength is given in the same building material and the distribution and interaction between fiber and polymer matrix.[7,8]

Mechanical strength and stiffness can be changed depending on the type and orientation of the building structure and also the proportions of the constituent materials. When a fabric is considered, the properties of the fibers and the yarns essentially govern the fabric properties, but in addition to the geometric criteria such as the fabric weave structure, or the knitted or non-woven construction, cover factor, and the yarn crimp in woven fabrics must also be taken into account $[1,4]$.

The applied of textile fabrics has generally provided a lower composite manufacturing cost and a higher damage tolerance. Plain weaves fabrics are the most commonly used basic reinforcements for woven fabric composites. Woven fabric composites containing into structure holes or cut-outs are often found in structural applications, because in composites will create stress or strain concentrations and hence will reduce the mechanical properties $[1,2]$. The prediction of reduction in the mechanical properties originating by holes is important for the composite designers. In order, to obtain further new properties, several researchers have applied the technique of hybridization, where besides the structure of the fabric, thread type and composition come into play as part of research [1-4]. Nowadays, a common way to produce hybrids is by laminating reinforced by using different fibers. The aerospace industry applied many hybrid laminates of this kind in very different applications, such as on helicopter blades and flaps [2]. Hybrid woven fabrics with interwoven glass, carbon and aramide such as Kevlar fibers are also a fine way to combine the best characteristics of those fibers in an unique material [1-3].

The high-strength, high-modulus Kevlar 49 fiber is widely used today because of its superior properties. Aramid fibers are known for their large hardness and resistance to 
penetration. Due to their toughness aramid fibers are used where high impenetrability is required, e.g. bulletproof vests, bike tyres, airplanes wings, and sport equipment. Aramid fibers are a very important reinforcement for advanced composites, which were developed during the 1960s and first introduced commercially by DuPont in the 1970s under the trade name Kevlar_. Their high degree of toughness, associated with the failure mechanism of aramids, and damage tolerance promotes good impact/ballistic performance. When aramid fibers break, they do not fail by brittle cracking, as do glass or carbon fibers. Instead, the aramid fibers fail by a series of small fibril failures, where the fibrils are molecular strands that make up each aramid fiber and are oriented in the same direction as the fiber itself. These many small failures absorb much energy and, therefore, result in very high toughness.[8]

The conventional textile structures are produced by weaving or knitting techniques, and weaving is the oldest technique for production of textile structures. This technique is based on the orthogonal interweaving of two yarn systems warp and weft. In order to allow a wide variety of structures, which differ according to the programming and properties of the yarns that make them. However, most derived from three fundamental structures: taffeta, twill and satin. These structures are being distinguished by the frequency of interlacing and / or degree of sequence in the arrangement of the yarns in the formation of the fabric.

The efficiency of a fibrous reinforcement depends on the type, length, volumetric fraction and orientation of the fibers during the mechanical test. The ideal choice of these parameters significantly influences one or more of the following characteristics of composite materials such as: density, tensile strength, compressive strength, compressive strength modulus, fracture and fatigue performance, impact load response, cost and properties thermal and electrical [7]

In this work, Kevlar nonwoven, obtained by cutting apart of the bulletproof, as used for reinforced polyester composites and kevlar fabrics manufacturing using handcraft process reinforced polyester will be tested using .38 weapons in close range in order to simulate a real situation (confrontation). The impact properties of the reinforcements will also be determined in the same situations and their behavior after tests are compared.

\section{EXPERIMENTAL}

In this study, two composites were produced: kevlar nonwoven reinforced polyester resin (CKNW) and kevlar fabrics reinforced polyester resin (CKF). Nonwoven fabric is obtained by dismantling a bulletproof vest used for military police and their material as supplied for BPChoque/RN (Figure 1). The fabrics were developed in laboratory scale using handloom machine for producing of aramid plain woven fabrics using twill structure (Figure 2).

The composite was produced using compression molding. Laminate made of layers of biaxial fabrics produced using Kevlar 49 fibers supplied for Dupont and development in laboratorial scale using handloom machine. The structure of the fabrics is twill. Layers of fabrics and nonwoven fabrics are cutup with the mold dimensions (200x150 mm) and disposed in the mold. The polyester resin is catalyzed using Butanox M50 at 1\% was poured over the fabrics. The mold closed and the system pressed less than 5 ton for $12 \mathrm{~h}$ at room temperature.

The ballistic test was performed in order to simulate a real confrontation situation. In this case, the samples were fixed in a metal support, Figure 3, using a adhesive tape and the distance of the shot was of 5 meters. This test was conducted at BPchoque / RN and the commander of the Squad unit was responsible for the shots. The weapon used was a .38 gun and .40 gun with exclusive police ammunition, with a high explosion factor. In this test 3 samples of the reinforcements and composites were evaluated. Composite C1 - bulletfrof reinforced polyester, 46\%; Composite T3 - fabric twill reinforced polyester, 30,5\%; Composite T3 - fabric and nonwoven kevlar reinforced polyester, 17\% 


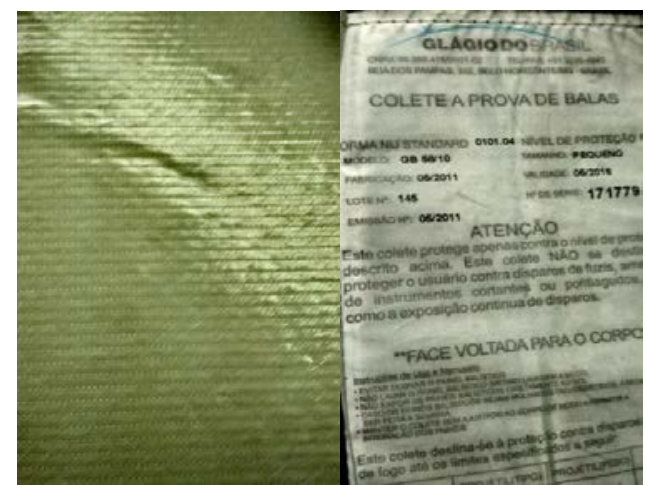

Figure 1- nonwoven fabrics for bulletproof

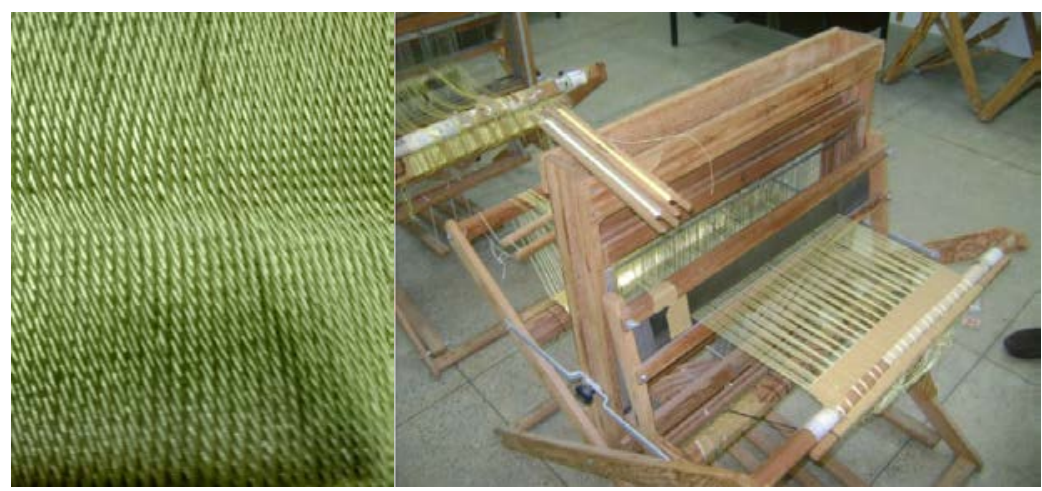

Figure 2- Fabric manufactured using handloom machine

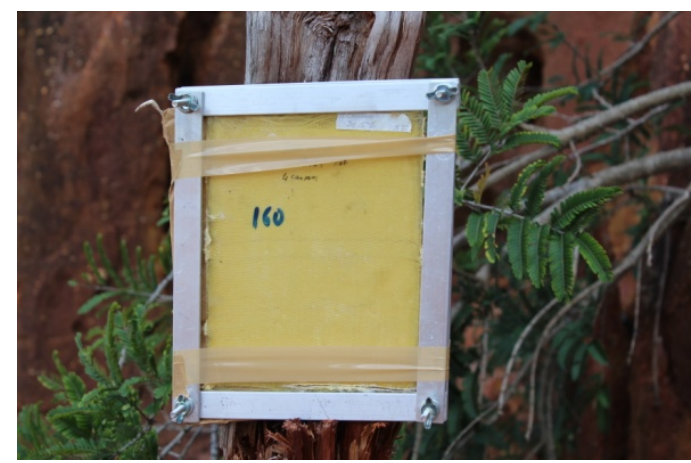

Figure 3- Sample fixed for gunshot test

\section{RESULTS AND DISCUSSION}

The results after the gunshot test demonstrated the efficiency of the reinforcements in the ballistic for bulletproof vest and the developed fabrics. However it is necessary to consider that the sample of the bulletproof vest is composed of 32 unidirectional kevlar layers in a $90^{\circ} /$ $-90^{\circ}$ configuration, while the woven sample consists of 4 layers in the same configuration. After the test, it was observed that the projectile, Figures 4 and 5 did not perforate the samples. This fact evidences the feasibility of using the fabric as a ballistic application. Although an evaluation of the transmission of impact energy in the human body is required. 


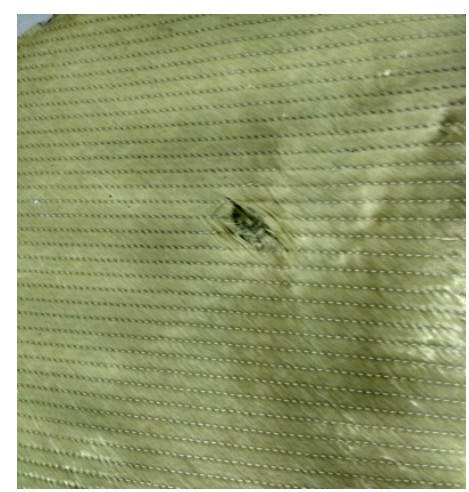

Figure 4- Bulletproof vest after gunshot test

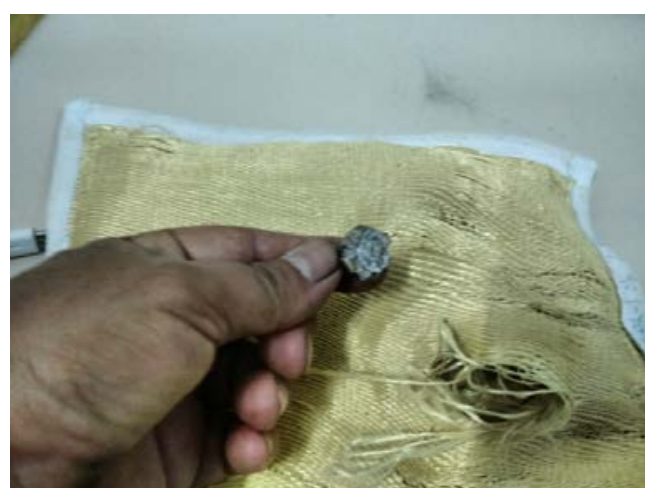

Figure 5- Fabric bulletprof sample after gunshot test

The performance of the composite under gunshot test for polyester reinforced kevlar fabrics of the composite was performed in a 3 different samples. The target is composed of a ballistic plate, a vest structure and a polyurethane foam. After gun shot test all parts were evaluated in relation to the degree of perforation and damage. For all composites the ballistic plates acting after the shooting test, all the ballistic plates acted to support the bullet and even after different calibers did not present a critical fracture. These results are indicative that the developed composites are efficient for use as a ballistic plate (figures 6 a 8). The profile of damage after visual analysis as possible observed delamination under hight impact, but not broken. This result is indicative that the material developed can be used in shields, if the dissipation impact energy of the projectile's is taken into account. Although perforation in the plate occurs the projectiles were housed in the structure of the bulletprof.

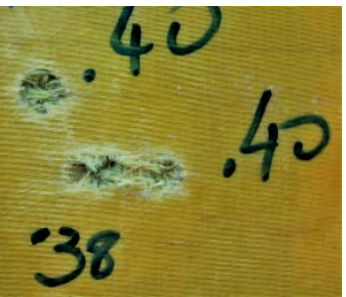

Figure 6 - Composite T3 after shotting test

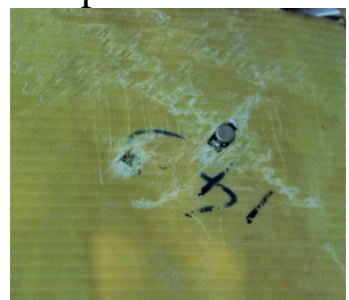

Figure 7 - Composite C1 after shotting test 


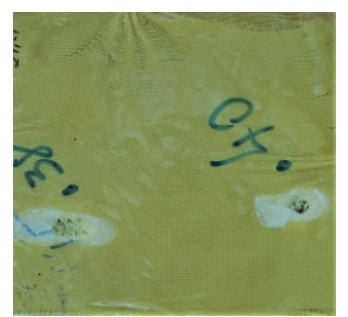

Figure 8 - Composite H1 after shotting test

\section{CONCLUSIONS}

The results showed the effective action of the composites developed for application in shields. Independently of the reinforcement contents, all the composites presented resistance to shooting using caliber, 38 and 40 . For the use of the caliber; 40 the material presented a very satisfactory result, considering the level of damage of this type of ammunition.

\section{ACKNOWLEDGEMENTS}

We are indebted to T.C. Rodrigo Trigueiro BP Choque/RN for support and performance of the shooting tests.

\section{REFERENCES}

[1] Holme; Adhesion to textile fibres and fabrics International Journal of Adhesion \& Adhesives 19 (1999) 455\} 463

[2] Manohar G. Kollegal and Srinivasan Sridharan; Strength Prediction of Plain Woven Fabrics; Journal of Composite Materials, V34 - 3, 2000, 240-257

[3] Horrocks, A.R and Anand, S.C - Handbook of Technical Textiles; CRC Press 2000.

[4] Reinhart,T.J.; "Introduction to Composites, in Engineered Materials Handbook, Composites", vol.1 - ASM International, Metals Park, EUA, 1987

[5] Hufenbach, W.; Böhm, R.; Kroll, L.; Langkamp, A- "Theoretical and experimental investigation of anisotropic damage in textile reinforced composite structures". Mechanics of Composites Vol. 40 (6), 519-532; 2004.

[6] H.L.Gower; D.S.Cronin; A.Plumtree - Ballistic impact response of laminated composite panels; International Journal of Impact Engineering; V35, Issue 9,2008, 1000-1008

[7] Jang-Kyo Kim; Man LungSham; Impact and delamination failure of woven-fabric composites; Composites Science and Technology; V 60, Issue 5, 2000, 745-761

[8] Bryan A.Cheeseman andTravis A.Bogetti; Ballistic impact into fabric and compliant composite laminates; Composite Structures; V61, Issues 1-2, 2003, 161-173 